\title{
On the non-neutrality of profit taxation in a Cournot oligopoly with environmental effects
}

\author{
Davide Dragone* Luca Lambertini* ${ }^{*}$ Arsen Palestini* \\ *Department of Economics, University of Bologna \\ Strada Maggiore 45, 40125 Bologna, Italy \\ fax $+39-051-2092664$
}

davide.dragone@unibo.it; luca.lambertini@unibo.it; palestini@math.unifi.it

$\S$ ENCORE, University of Amsterdam

Roeterstraat 11, WB1018 Amsterdam, The Netherlands

March 17, 2009 


\begin{abstract}
We consider the joint effect of profit and Pigouvian taxation in a model of imperfect competition. We show that, when both profit taxation and Pigouvian taxation/subsidy are used, the former is no longer neutral. The two fiscal tools are substitutes, and for any profit taxation rate there exists a unique Pigouvian tax that entails the first best outcome as an equilibrium. Our analysis therefore suggests that policy makers in charge of different taxation policies should coordinate in order to optimally design the tax menu for firms.
\end{abstract}

JEL codes: H23, H25, L13, Q51

Keywords: externalities, Pigouvian taxation, oligopoly 


\section{Introduction}

There exists a relatively large literature on profit taxation in static models of imperfect competition (Levin, 1985; Besley, 1989; Delipalla and Keen, 1992; Dung, 1993; Denicolò and Matteuzzi, 2000; Ushio, 2000, inter alia). A well established result of this literature is that the taxation of operative profits (defined as the profits gross of fixed costs) is neutral, in that it does not affect first order conditions on market variables.

A parallel stream of research focuses on the effectiveness of a Pigouvian taxation/subsidy in inducing the firms to internalise the externalities involved in the production process (Benchekroun and Long, 1998, 2002; Karp and Livernois, 1994; Damania, 1996, inter alia). The effect of this form of taxation/subsidy is to distort the incentives for the firm in order to make the choice of its market variable consistent with the outcome that maximises social welfare.

In this paper we consider the joint effect of profit and Pigouvian taxation in a model of imperfect competition. We show that, when both profit taxation and Pigouvian taxation/subsidy are used, the former is no longer neutral. The two fiscal tools behave as substitutes, and for any profit tax rate there exists a unique Pigouvian tax rate that entails the first best outcome as an equilibrium. This prompts for a coordination effort among the policy makers in charge of designing optimally the different tax rates to which firms are subject in industries featuring environmental externalities. 


\section{Profit taxation is not neutral}

Consider a market with demand function $p=p(Q)$, with $p(Q)$ decreasing and non-convex in $Q$, where $Q$ is aggregate output. Production costs for each firm $i=1,2, \ldots n$ are given by $C_{i}=C\left(q_{i}\right)+f$, with $\partial C\left(q_{i}\right) / \partial q_{i}>0$ and the fixed cost $f>0$. The latter is taken to be small enough to ensure that individual profits be non-negative at the Cournot equilibrium with $n$ firms. Supplying the final good to the market entails a negative externality $S=S(Q)$, where $Q=\sum_{i=1}^{n} q_{i}$, with $\partial S(Q) / \partial Q>0$ and $\partial S(Q) / \partial q_{i}>0$ for all $i=1,2, \ldots n .{ }^{1}$ Let $\theta \geq 0$ be a tax rate to be paid by each firm as a function of the externality and let $t \in[0,1)$ be the tax rate on operative profits. This implies that the firm's profit is

$$
\pi_{i}(Q)=\left[p(Q) q_{i}-C\left(q_{i}\right)\right](1-t)-f-\theta S(Q) \geq 0 .
$$

If firms compete à la Cournot-Nash, the first order condition for each firm $i$ is

$$
\frac{\partial \pi_{i}}{\partial q_{i}}=\left[\frac{\partial p(Q)}{\partial q_{i}} q_{i}+p(Q)-\frac{\partial C\left(q_{i}\right)}{\partial q_{i}}\right](1-t)-\theta \frac{\partial S(Q)}{\partial q_{i}}=0
$$

which identifies a maximum iff

$$
\frac{\partial^{2} p(Q)}{\partial q_{i}^{2}}<\frac{\theta \partial^{2} S(Q) / \partial q_{i}^{2}}{(1-t) q_{i}}+\frac{1}{q_{i}}\left[\frac{\partial^{2} C\left(q_{i}\right)}{\partial q_{i}^{2}}-2 \frac{\partial p(Q)}{\partial q_{i}}\right]
$$

Clearly, when $\theta=0$, the choice of the tax rate on profit is irrelevant and the optimal level of individual output is the solution of the expression in the square bracket ${ }^{2}$. Nevertheless, this conclusion no longer holds if $\theta$ is positive.

\footnotetext{
${ }^{1} \mathrm{~A}$ similar reasoning holds when the externality is positive, provided the signs are changed to take into account the introduction of a Pigouvian subsidy.

${ }^{2}$ The case where $\frac{\partial S(Q)}{\partial q_{i}}=0$ is not interesting, as this implies that the firm has no influence on the externality.
} 
Lemma 1 Provided firms are subject to any Pigouvian tax rate $\theta>0$, then profit taxation is non-neutral.

Define as $q_{i}^{*}(t, \theta)$ the solution to $(2)$. Then, using the implicit function theorem, one can examine the effect of the taxation menu on the optimal output of each individual firm, as well as the interplay between the two forms of taxation, to prove:

Proposition 2 In correspondence of the optimal output decision of the generic firm i, Pigouvian taxation and profit taxation are strategic substitutes.

Proof. It suffices to observe that

$$
\frac{d \theta}{d t}=-\frac{\partial^{2} \pi_{i}}{\partial q_{i} \partial t} / \frac{\partial^{2} \pi_{i}}{\partial q_{i} \partial \theta}=-\frac{q_{i} \cdot \partial p(Q) / \partial q_{i}+p(Q)-\partial C\left(q_{i}\right) / \partial q_{i}}{\partial S(Q) / \partial q_{i}}<0
$$

because the numerator is necessarily positive from (2). Hence the tax menu available to the policy maker(s) is characterised by a negative marginal rate of substitution between the two forms of taxation.

\section{Example}

Consider an oligopolistic market where $n$ symmetric firms produce a homogeneous good. The market demand function is $p=a-Q$ where $Q \equiv \sum_{i=1}^{n} q_{i}$ and $q_{i}$ is firm $i$ 's output $i, i=1,2, \ldots n$. Technology is the same for all firms and it is summarised by the cost function $C\left(q_{i}\right)=c q_{i}-f$, where $c \geq 0$. This entails that firm $i$ 's net profits in absence of any taxation are $\pi_{i}=(p-c) q_{i}-f$.

Supplying the final good entails a negative environmental externality $S=$ $\sum_{i=1}^{N} b q_{i}$, with $b \geq 0$, that negatively affects consumers' utility. The social planner chooses the Pigouvian tax rate $\theta \geq 0$ that each firm has to pay as 
a function of the amount of the environmental externality produced by the industry. Moreover, operative profits are taxed at the rate $t \in[0,1]$, so that the net after-tax profits of firm $i$ are

$$
\pi_{i}=(p-c) q_{i}(1-t)-f-\theta S
$$

The present game has a two-stage structure: in the first stage, the social planner chooses the taxation rate on profits $t$ and the taxation rate on the negative externality $\theta$ produced by the industry in order to maximise social welfare

$$
S W=n \pi_{i}+C S \text {. }
$$

Total tax revenues, $T=n\left[(p-c) q_{i} t+\theta S\right]$ are transferred to consumers, whose surplus reads as

$$
C S=\frac{Q^{2}}{2}-S+T
$$

In the second stage, firms compete à la Cournot-Nash.

\section{Equilibrium analysis}

The solution concept is subgame perfection by backward induction. This requires determining the optimal output produced by each firm as a function of the taxes chosen by the social planner as the leader in the first stage. From the first order condition at the second stage, one obtains:

$$
q_{i}^{*}(t, \theta)=\frac{1}{1+n}\left(a-c-\frac{b \theta}{1-t}\right)
$$

for every $i=1,2, \ldots n$. As $\partial q_{i}(t, \theta) / \partial t<0$ for all $\theta>0$ and $\partial q_{i}(t, \theta) / \partial \theta<0$ for all $t \in[0,1)$, we can state the following: 
Lemma 3 For $\theta>0$, the individual output level decreases (increases) if the taxation rate on operative profits and on the environmental externality increases (decreases).

Note also that, if the social planner does not tax the environmental externality, then the tax rate on variable profits does not affect the optimal individual output.

Substituting (8) in (5) yields the following expressions for the net individual profits, the amount of externality and total revenues:

$$
\begin{gathered}
\pi_{i}^{*}=\frac{(1-t)\left[(a-c)^{2}(1-t)-f(1+n)^{2}\right]-b \theta\left[(a-c)\left(1+n^{2}\right)(1-t)+b n^{2} \theta\right]}{(1+n)^{2}(1-t)} \\
S^{*}=\frac{n b}{1+n}\left(a-c-\frac{b \theta}{1-t}\right) \\
T^{*}=\frac{n[b \theta-(a-c)(1-t)][b n \theta(1-n(1-t))-(a-c)(1-t) t]}{(1+n)^{2}(1-t)^{2}}
\end{gathered}
$$

Plugging the above expressions in (6) one obtains:

$$
\begin{aligned}
S W^{*}= & -f n+ \\
& \frac{n}{2(1+n)^{2}(1-t)^{2}}\left[2 b c(1+n)+\left(a^{2}+c^{2}-2 f n\right)(2+n)+\right. \\
& -2 a(b+2 c+b n+c n)(1-t)^{2}+ \\
& \left.+2 b(a-b-c-c n)(1-t) \theta-b^{2} n \theta^{2}-2 f\right] .
\end{aligned}
$$

Now, solving $\partial S W^{*} / \partial \theta=0$, one has

$$
\theta^{*}=\frac{(1-t)[b(n+1)-a+c]}{b}>0
$$

for all $b>(a-c) /(n+1)$, where the lower bound to $b$ coincides with the optimal Cournot-Nash output in absence of Pigouvian taxation, $q^{C N}(\theta=0)$. 
From (13), we draw an immediate implication concerning the elasticity of substitution:

$$
\left|\varepsilon_{\theta t}\right|=-\frac{\partial \theta^{*}}{\partial t} \cdot \frac{t}{\theta^{*}}=\frac{t}{1-t} \in[0,1) \forall t \in[0,1 / 2) .
$$

This entails that, if different authorities manoeuvre the two tax rates, they should coordinate in order to achive the welfare maximisation that, in principle, is their common objective. In practice, the alternative between taxing and subsidising firms in order to regulate the amount of pollution depends on parameter $b$. This amounts to saying that the agency in charge of the environmental policy should inform the fiscal authority about the marginal environmental impact of the technology employed by firms operating in the industry under examination.

Given the optimal Pigouvian policy being adopted, the equilibrium output for the individual firm is

$$
q_{i}^{*}\left(\theta^{*}\right)=\frac{a-c-b}{n}>0 \forall b \in[0, a-c),
$$

with $q_{i}^{*}\left(\theta^{*}\right)<q^{C N}(\theta=0)$ for all $b>(a-c) /(n+1)$, entailing that, whenever firms are subject to a positive Pigouvian tax rate aimed at reducing the environmental externality, they restrict production as compared to the Cournot-Nash benchmark where Pigouvian taxation is absent.

The intuitive interpretation of the above result is that, if polluting emissions are very relevant, then the external effect dominates the price effect, and therefore the planner wants firms to reduce output although this involves a price increase. Exactly the opposite holds if the balance between the two effects speaks in favour of the price effect, whereby if $b<(a-c) /(n+1)$, then $\theta^{*}$ indeed becomes a subsidy to firms notwithstanding the presence of the externality. 
The resulting social welfare level is $S W\left(\theta^{*}\right)=\left[(a-c-b)^{2}-2 n f\right] / 2$, which coincides with the first best level that the planner would attain by choosing directly the aggregate industry output instead of taxing polluting emissions of the $n$ Cournot oligopolists (to this regard, see Benchekroun and Long, 1998). 


\section{References}

[1] Benchekroun, H. and N.V. Long (1998). Efficiency inducing taxation for polluting oligopolists. Journal of Public Economics, 70, 325-342.

[2] Benchekroun, H. and N.V. Long (2002). On the multiplicity of efficiencyinducing tax rules. Economics Letters, 76, 331-336.

[3] Besley, T. (1989). Commodity taxation and imperfect competition: a note on the effects of entry. Journal of Public Economics, 40, 359-367.

[4] Damania, D. (1996). Pollution taxes and pollution abatement in an oligopoly supergame. Journal of Environmental Economics and Management, 30, 323-336.

[5] Delipalla, S. and M. Keen (1992). The comparison between ad valorem and specific taxation under imperfect competition. Journal of Public Economics, 49, 351-367.

[6] Denicolò, V. and M. Matteuzzi (2000). Specific and ad valorem taxation in asymmetric Cournot oligopolies. International Tax and Public Finance, 7, 335-342.

[7] Dung, T.H. (1993). Optimal taxation and heterogeneous oligopoly. Canadian Journal of Economics, 26, 933-947.

[8] Karp, L. and J. Livernois (1994). Using automatic tax changes to control pollution emissions. Journal of Environmental Economics and Management, 27, 38-48. 
[9] Levin, D. (1985). Taxation within Cournot oligopoly. Journal of Public Economics, 27, 281-290.

[10] Ushio, Y. (2000). Welfare effects of commodity taxation in Cournot oligopoly. Japanese Economic Review, 51, 268-273. 